\title{
O romance no ensino da Física Moderna e Contemporânea: uma proposta metodológica
}

\author{
Maria Natália Mouta de Oliveira ${ }^{1}$ \\ Gilberto Dantas Saraiva ${ }^{2} \mathrm{C}$ \\ Maria Sonia Silva de Oliveira Veloso ${ }^{3}$ \\ Antônio Joel Ramiro de Castro ${ }^{4}$ \\ ${ }^{1}$ Secretaria Municipal de Educação Crateús, Ceará; ${ }^{2}$ Universidade Estadual do Ceará (UECE); ${ }^{3}$ Universidade \\ Federal de Roraima (UFRR); ${ }^{4}$ Universidade Federal do Ceará (UFC), Brasil
}

Resumo. O ensino de Física no Brasil está voltado para a memorização e a preparação para provas, tornando o processo de ensino aprendizagem superficial. Os conceitos são ensinados na maioria das vezes sem uma contextualização e uma aproximação com o cotidiano, e ainda na Educação Básica tradicionalmente a Física Moderna e Contemporânea (FMC) não é parte obrigatória, tendo em vista a sua complexidade em conceitos e fórmulas. Diante desse contexto, propõem-se nessa pesquisa o uso de leituras paradidáticas como metodologia para trabalhar a FCM na Educação Básica. A pesquisa ocorreu de forma remota com 80 estudantes, com a utilização de um romance de autoria própria, onde são abordados temas da FMC. O trabalho tem como objetivo apresentar os conceitos da FMC, com uma linguagem mais acessível, inspiradora, visando a aprendizagem dos fenômenos físicos através da leitura. Os resultados mostraram um percentual de acerto maior que $75 \%$ para as questões fenomenológicas e conteudista. Porém, sabe-se, que o ensino de Física é desafiador e que essa proposta não resolve todos os problemas, mas, pode ser um dos caminhos para consolidar melhor o ensino dessa ciência, que muito tem a contribuir com o desenvolvimento da sociedade.

Palavras-chave: leitura; aprendizagem; ensino de Física.

La novela en la enseñanza de la Física Moderna y Contemporánea: una propuesta metodológica

Resumen. La enseñanza de la Física en Brasil se centra en la memorización y preparación para las pruebas, haciendo que el proceso de enseñanza sea un aprendizaje superficial. Los conceptos se imparten la mayor parte del tiempo sin una contextualización y aproximación con la vida cotidiana, y aún en Educación Básica, la Física tradicionalmente Moderna y Contemporánea (FMC) no es una parte obligatoria, dada su complejidad en cuanto a conceptos y fórmulas. Ante este contexto, esta investigación propone el uso de lecturas paradidácticas como metodología para trabajar la FCM en Educación Básica. La investigación se realizó de forma remota con 80 estudiantes, con el uso de una novela de su propia autoría, donde se abordan temas de FMC. El trabajo tiene como objetivo presentar los conceptos de FMC, con un lenguaje más accesible e inspirador, con el objetivo de aprender los fenómenos físicos a través de la lectura. Los resultados mostraron un porcentaje de acierto superior al $75 \%$ para las cuestiones fenomenológicas y de contenido. Sin embargo, se sabe que la enseñanza de la Física es desafiante y que esta propuesta no resuelve todos los problemas, pero puede ser una de las formas de consolidar mejor la enseñanza de esta ciencia, que tiene mucho que aportar al desarrollo de la sociedad.

Palabras clave: lectura; aprendizaje; enseñanza de la Física.

The novel in the teaching of Modern and Contemporary Physics: a methodological proposal Abstract. The teaching of Physics in Brazil is focused on memorization and preparation for tests, making the teaching process superficial learning. The concepts are taught most of the time without a contextualization and an approximation with the everyday, and still in Basic Education traditionally Modern and Contemporary Physics (FMC) is not a mandatory part, in view of its complexity in concepts and formulas. Given this context, this research proposes the use of paradidactic readings as a methodology to work FCM in Basic Education. The research took place remotely with 80 students, with the use of a novel by her own authorship, where FMC themes are addressed. The work aims to present the concepts of FMC, with a more accessible, inspiring language, aiming at learning physical phenomena through reading. The results showed a percentage of correctness greater than $75 \%$ for the phenomenological and content issues. However, it is known that the teaching of Physics is challenging and that this proposal does not solve all the problems, but it may be one of the ways to better consolidate the teaching of this science, which has much to contribute to the development of society.

Keywords: reading; learning; Physics teaching. 


\section{Introdução}

O ensino de Física na Educação Básica deve promover a conexão com as diferentes áreas do conhecimento e sua contextualização com a realidade dos estudantes. No entanto, o ensino de Física ainda ocorre de forma tradicional através de memorização de fórmulas, de modo descontextualizado e não interdisciplinar. Devido a isto, os discentes demonstram um desinteresse pela disciplina, bem como dificuldade no processo de ensino aprendizagem, de relacionar o conteúdo com o cotidiano e ainda consideram a Física como uma extensão da Matemática.

De acordo com Moreira (2021), ainda existem muitos desafios no ensino de Física, pois, de forma geral os estudantes não aprendem, apenas memorizam fórmulas, conceitos e definições, que logo são esquecidos. Aprender Física, na sua visão é muito mais que decorar e dar respostas prontas, envolve a contextualização e a criticidade. Nesse contexto, surge a possibilidade de elaborar metodologias que promovam o caráter conceitual, reflexivo e poético da Física.

O ensino de Física na Educação Básica, de acordo com os autores Nunes e Macedo (2018) é restringido a conceitos clássicos, a Física Moderna e Contemporânea $(F M C)$ tradicionalmente não é parte obrigatória do currículo para essa etapa de ensino, mesmo sendo sugerida nos documentos oficiais.

Nessa perspectiva, de diminuir as lacunas no ensino de Física e inserir a FMC na Educação Básica, sugere-se nesta pesquisa, a utilização de metodologias alternativas, como os textos paradidáticos, pois, como apresentado por Moura (2017), a utilização de leituras paradidáticas, pode ampliar a capacidade dos estudantes não só na sua prática de leitura, como na interpretação, imaginação, entre outras habilidades.

Diante desse cenário, realizou-se uma pesquisa de campo com 80 estudantes, da Educação Básica e Ensino Superior, de forma remota por meio de um aplicativo, onde foi trabalhado um romance de autoria própria, com o objetivo de analisar as contribuições da leitura proposta, para a motivação e aprendizagem dos conceitos de Física.

Com os dados coletados, nota-se que a utilização da leitura do romance para ensinar FMC, foi considerado pelos estudantes uma metodologia que desperta o interesse e facilita a compreensão dos conceitos, alcançando-se dessa forma os objetivos pretendidos pela pesquisa.

\section{Referêncial teórico}

\subsection{O ensino de Física Moderna e Contemporânea na Educação Básica}

De acordo com autores Nunes e Macedo (2018), o ensino de Física no Brasil para a Educação Básica ainda é baseado na abordagem Clássica, com conceitos básicos de mecânica, ótica, termodinâmica e no máximo o de eletromagnetismo.

Atualmente vivemos em um cenário educacional em que a disciplina de física é ministrada mediante uma grade curricular que aborda os conteúdos da física clássica, como a mecânica clássica, a termodinâmica clássica e o eletromagnetismo (Nunes e Macedo, 2018, p. 1). 
Sabe-se, no entanto, que a Física Clássica não explica determinados fenômenos como o Efeito Fotoelétrico, que é compreendido somente a partir da Física Quântica que surgiu na segunda metade do século XIX. Moreira (2007) defende também que não faz sentido a Física ensinada nas escolas seja restrita aos conceitos clássicos que vão apenas até o século XIX.

Verifica-se dessa forma, que é inegável a relevância de se ensinar conceitos de FMC ainda na Educação Básica. Para os autores Silva e Almeida (2011), essa importância está relacionada ao fato de sua eficácia nas tecnologias modernas, como pode ser citado os lasers, supercondutores e transistores, que compõem muitos equipamentos utilizados pelos jovens de hoje. Adicionalmente, os autores mencionam a LDB, que defende um ensino de Física contextualizado, associado ao cotidiano do estudante.

Por estar diretamente relacionada às tecnologias modernas e pelo fato de documentos oficiais da educação brasileira (Lei de Diretrizes e Bases, Parâmetros Curriculares Nacionais, entre outros) defenderem um ensino mais contextualizado, mais ligado à cultura humana, é inegável a importância de se ensinar FMC no Ensino Médio, incluindo a Física Quântica (Silva e Almeida, 2011, p. 626).

As principais dificuldades para inserção de uma Física para além da Clássica na Educação Básica, de acordo com Nunes e Macedo (2018) é a matemática que descreve os fenômenos, pois envolve cálculos diferenciais que são um pouco avançados para esta etapa de ensino e os conceitos quânticos que por muitas vezes divergem do senso comum.

O formalismo matemático que trata da descrição quântica, os novos conceitos que fogem da Física Clássica e que desafiam o senso comum, os experimentos que abordam temáticas da Mecânica Quântica que as vezes são difíceis de serem compreendidos, são algumas dificuldades que o professor e o aluno devem enfrentar ao tratar o conteúdo de Física Quântica no ensino médio (Nunes e Macedo, 2018, p. 2).

Diante do exposto, percebe-se, que embora se tenha conhecimento sobre a importância do ensino de FMC para a Educação Básica, ainda existem muitas dificuldades na implementação dessa ideia, como pode ser citado a resistência de alguns professores, materiais inadequados, entre outras. Porém, a cada dia está crescendo o número de trabalhos, com o propósito de implementar esses conceitos e de melhorar o processo de ensino aprendizagem.

\subsection{Aprendizagem significativa crítica}

Moreira (2010) apresenta que a aprendizagem significativa é caracterizada por considerar a relação existente entre os conhecimentos novos que são adquiridos com os conhecimentos prévios, fortalecendo o que já se sabia antes e amadurecendo o novo que foi conhecido.

Moreira (2010) ainda destaca que a "aprendizagem significativa crítica: é aquela perspectiva que permite ao sujeito fazer parte de sua cultura e, ao mesmo tempo, estar fora dela" (Moreira, 2010, p. 7). Dessa forma o estudante, mesmo sendo parte 
de sua cultura, não será submetido por ela, ou seja, faz parte de um povo, mas tem suas próprias experiências, perspectivas, um sujeito ativo e crítico da sociedade em que vive.

É através dessa aprendizagem que ele poderá lidar construtivamente com a mudança sem deixar-se dominar por ela, manejar a informação sem sentir-se impotente frente a sua grande disponibilidade e velocidade de fluxo, usufruir e desenvolver a tecnologia sem tornar-se tecnófilo (Moreira, 2010, p.7).

O processo de ensino aprendizagem através da interação entre a nova informação abordada com a estrutura cognitiva do aluno é argumentado nos princípios da aprendizagem significativa de Ausubel. Além disso, indica que a aprendizagem significativa ocorre quando o aluno encontra sentido no que está aprendendo e relaciona esses conceitos através de pontes cognitivas ou subsunçores de aprendizagem, que irão relacionar o novo com o que o aluno já sabe.

Ausubel também apresenta estratégias facilitadoras de aprendizagem como: os organizadores prévios, os mapas conceituais e os diagramas. De modo análogo, Moreira (2010), apresenta também onze princípios, os quais ele considera facilitadores da aprendizagem significativa crítica. Dentre estes destaca-se o terceiro princípio, o Princípio da não centralidade do livro didático, que trata do uso de documentos, artigos e outros materiais educativos, bem como da diversidade de materiais instrucionais.

Nesse princípio da teoria de Moreira (2010), é apresentado que o livro texto é apenas mais uma ferramenta que os professores podem utilizar para alcançar seus objetivos, a aprendizagem dos estudantes, porém, não é a única que pode ser utilizada, e sugere os contos, artigos, entre outras obras que podem sim, auxiliar muito bem na aprendizagem dos estudantes.

Artigos científicos, contos, poesias, crônicas relatos, obras de arte e tantos outros materiais representam muito melhor a produção do conhecimento humano. São maneiras de documentar de maneira compacta o conhecimento produzido (Moreira, 2010, p. 10).

Utilizar materiais alternativos na visão de Moreira (2010), é um princípio facilitador da aprendizagem e quando bem utilizados com responsabilidade e coerência, podem trazer excelentes resultados.

A utilização de materiais diversificados, e cuidadosamente selecionados, ao invés da "centralização" em livros de texto é também um princípio facilitador da aprendizagem significativa crítica. (Moreira, 2010, p. 10).

\subsection{A utilização de romances no ensino de Física}

O romance, de acordo com o que se encontra na literatura é uma narrativa que se organiza em sequências de fatos que estão interligados entre si e que acontecem em um tempo determinado, sendo também, um dos gêneros textuais mais populares entre o público jovem.

De modo geral, o ensino deve ser respaldado na leitura e mesmo em componentes curriculares como a Física cabe sim, a utilização de textos que podem variar desde o livro didático, a romances, poesias, textos científicos, entre outros. 
O espaço de leitura pode ser realizado através dos livros didáticos e aos que eles denominam de "textos alternativos", em que se enquadrariam os romances, poesias, textos de divulgação científica e textos jornalísticos (Gomes, 2011, p. 72).

Para o ensino de Física, muitas dessas leituras podem ser utilizadas, pois segundo Zanetic, 1990, essa ciência tem seus mistérios próprios, que pode muito bem se enquadrar em um romance, podendo ser assim aproveitado para diversificação das aulas, porém, reitera que esta não deve ser a única alternativa de metodologia para o ensino da Física.

A Física também é cultura. A Física também tem seu romance intricado e misterioso. Isso não significa a substituição da Física escolar "formulista" por uma Física "romanceada". O que desejo é fornecer substância cultural para esses cálculos, para que essas fórmulas ganhem realidade científica e que se compreenda a interligação da Física com a vida intelectual e social em geral (Zanetic, 1990, p. 8).

De acordo com os autores Setlik e Higa (2020), as pesquisas em ensino de Física apresentam, que a leitura proporciona muito mais que o aprendizado de conceitos, esta contribui para a formação integral dos estudantes e ainda consegue-se estabelecer relações da Física com outras áreas do conhecimento como a Literatura.

$\mathrm{Na}$ área de pesquisas em ensino de Física, estudos apontam, por exemplo, possibilidades que a leitura de textos escritos proporciona para o aprendizado de conceitos físicos no Ensino Médio, como uma formação crítica e a possibilidade de estabelecer relações da Física com outras áreas do conhecimento (Setlik e Higa, 2020, p. 3).

A princípio, pode-se considerar que a Física e a Literatura são duas coisas distintas e difíceis de serem trabalhadas juntas, no entanto, os autores Santos et al. (2017), consideram que esta metodologia pode ser, uma das formas de se explorar a imaginação do estudante, tão necessária para a compreensão dos conceitos físicos.

À primeira vista, física e literatura parecem duas disciplinas distantes. Mas o físico apaixonado por arte acredita que a literatura permite investigar todo o contexto sociocultural em que a ciência está inserida, além de explorar o imaginário do aluno (Santos et al., 2017, p. 1149).

Santos et al. (2017), também acrescentam que essa ferramenta pode vir a fortalecer o ensino da FMC, preenchendo possíveis lacunas deixadas pelos livros textos tradicionais.

Não só de fórmulas vivem as aulas de física. Os romances podem ser um poderoso instrumento para preencher lacunas deixadas pelos livros didáticos nas explicações de conceitos da física moderna (Santos et al., 2017, p. 1149).

\subsection{Ensino remoto}

O ano de 2020 foi marcado por um cenário educacional atípico: mudanças de hábitos, alterações na mediação quanto ao ensino formal e o uso de ferramentas digitais. Adequações necessárias para a continuidade do ensino, tendo em visto o grave problema de saúde pública, ocasionado pelo vírus SARS-CoV-2, que colocou o mundo em quarentena. 
Dessa forma o ensino da rede pública e privada brasileira em 2020, deram continuidade às suas atividades educacionais de forma remota, podendo se estender esse formato até o ano de 2021, como apresentado na resolução do Concelho Nascional de Educação (CNE) regulamentado na Lei $n^{0}$ 14.040, de 18 de agosto de 2020, que amplia as normas excepcionais de atendimento educacional e estende até o final de 2021, a permissão para que as instituições de ensino pública e particular a darem continuidade às atividades remotas para o ensino básico e superior.

Respaldados noque diz a Lei de Diretrizes e Bases da Educação Nacional (LDB), parágrafo $4^{\circ}$ do Art. 32, nas orientações do CNE e CEE-CE parecer N ${ }^{\circ} 205 / 2020$, de 22 de julho de 2020, instalou-se em todo estado do Ceará o enino remoto, desde a educação infantil ao ensino superior nas unidades educacionais públicas e privadas.

E mesmo os desafios desse formato de ensino sendo significativos, podendo ser citados o acesso a internet de boa qualidade, a falta de equipamentos eletrônicos, entre outros, o autor Arruda 2020, considera que este, é indispensável, para que assim possa ser mantido o vínculo entre professores e alunos, o que se enquadra muito bem na situação vivenciada.

Podemos afirmar, portanto, que a educação remota é um princípio importante para manter o vínculo entre estudantes, professores e demais profissionais da Educação (Arruda, 2020, p. 266)

O ensino remoto é a experiência de ensinar a distância, com o uso de tecnologias ou não, tanto para exposição dos conteúdos como para o acompanhamento das/ os estudantes no desenvolvimento de suas atividades. Prática necessária para o atual cenário educacional, pois a volta as aulas presenciais de acordo com os especialistas ainda não ésegura.

\section{Metodologia}

Para atender os objetivos traçados, foi realizada uma pesquisa de campo com 80 estudantes, sendo destes, 77 da rede pública de ensino (38 Ensino Fundamental e 28 Ensino Médio e 11 do Ensino Superior), afim de compreender como a leitura paradidática proposta: Memórias de Luiza, um romance sobre a FMC, pode motivar e facilitar a aprendizagem dos conceitos físicos pelos estudantes.

A pesquisa de campo caracteriza-se pelas investigações em que, além da pesquisa bibliográfica e/ou documental, se realiza coleta de dados junto a pessoas, com o recurso de diferentes tipos de pesquisa (pesquisa ex-post-facto, pesquisa-ação, pesquisa participante, etc.) (Fonseca, 2002, p. 50).

No desenvolver do romance, são explicados temas relevantes dentro da Física Moderna e Contemporânea, como por exemplo o Efeito Fotoelétrico, Princípio da Incerteza, Dualidade Onda-Partícula, O novo Modelo Atômico como também algumas aplicações dessa ciência para o cotidiano dos estudantes. No final é descrito as características quânticas do Universo e uma correção da personagem com a cientista Marie Curie.

A pesquisa foi realizada de forma remota, em decorrência do isolamento social, nos meses de dezembro de 2020 e janeiro de 2021, com a utilização de um aplicativo (Física e Romance), acessível no endereço: (https://app.vc/fisica_e_romance). 
No aplicativo estão disponíveis: o romance, um questionário (https://bit. ly/3mMaGmp) a ser respondido pelos estudantes, uma galeria com todas as imagens e sua respectiva descrição e o contato dos autores para quaisquer dúvidas, críticas e sugestões.

O aplicativo apresenta uma linguagem simples, bem didática, acessível a todo o público e foi disponibilizado em grupos de estudo, e também na loja de aplicativos, podendo ser utilizado por outros estudantes e professores.

\section{Análise e resultados}

Com os dados coletados, temos que os estudantes que participaram da pesquisa são dos municípios de: Crateús, Mombaça, Choró, Boa Viagem, Caucaia e Quixeramobim do Estado do Ceará, como especificado no gráfico 01.

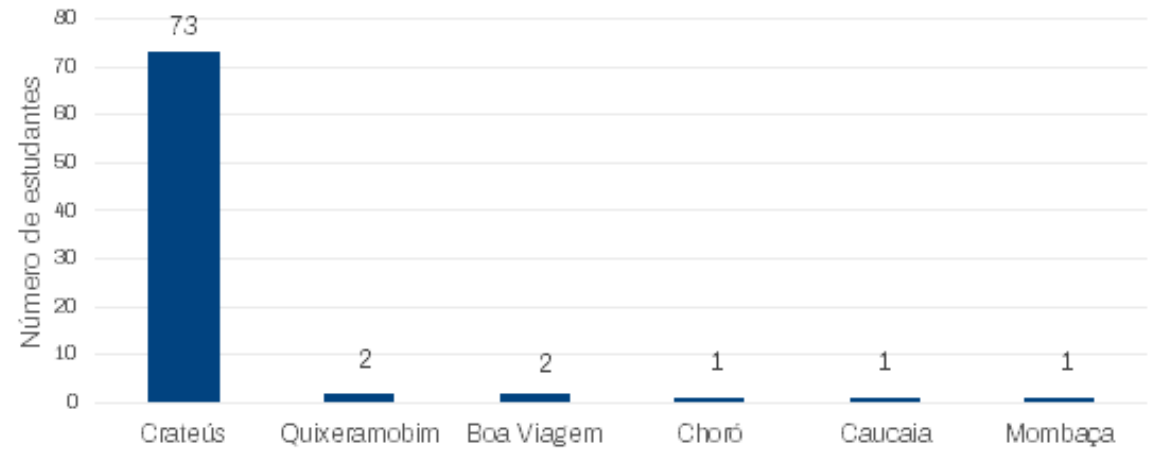

Gráfico 01. Localização dos estudantes participantes da pesquisa Fonte: Elaborado pelos autores (2021).

O gráfico 02 mostra que 47,5\% dos estudantes estão cursando o Ensino Fundamental $-2^{\circ}$ ciclo ( $6^{\circ}$ ao $9^{\circ}$ ano), seguindo do Ensino Médio com 35\%, onde $46 \%$ destes estão no $1^{\circ}$ ano e $43 \%$ no $3^{\circ}$ ano e o Ensino Superior, com $17,5 \%$, sendo: $21,4 \%$ discentes do Mestrado Nacional Profissional em Ensino de Física (MNPEF), 43\% do curso de Química, 21,4\% de Engenharia de Minas e 14,2\% de outros.

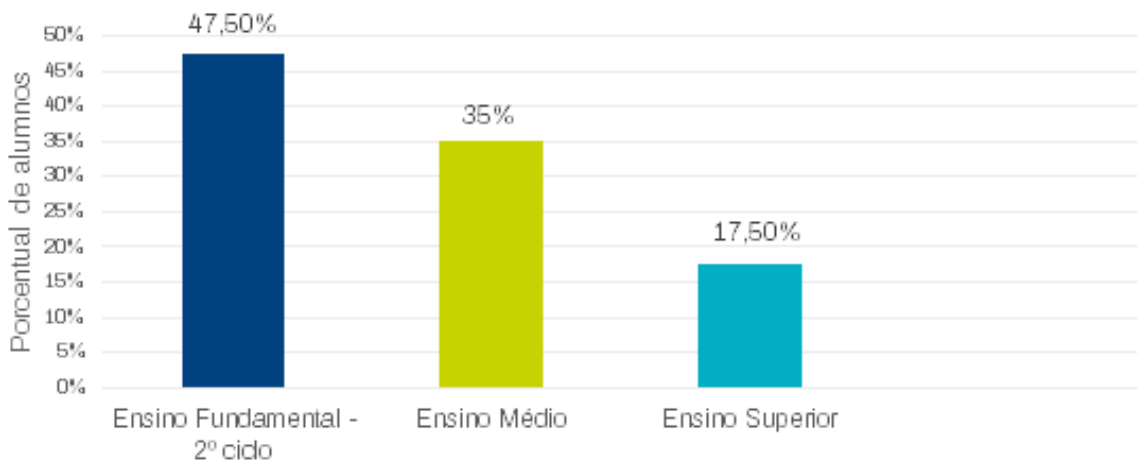

Gráfico 02: Etapa de ensino dos estudantes Fonte: Elaborado pelos autores (2021). 
De início, o questionário apresentava questões situacionais, como localização, escolaridade, entre outras. Em sequência foi questionado aos estudantes, se eles conheciam os temas da FMC apresentados no romance, ou seja, se já tinham algum conhecimento prévio sobre o assunto, e a maioria (55\%) como apresentado no gráfico 03 respondeu que sim.

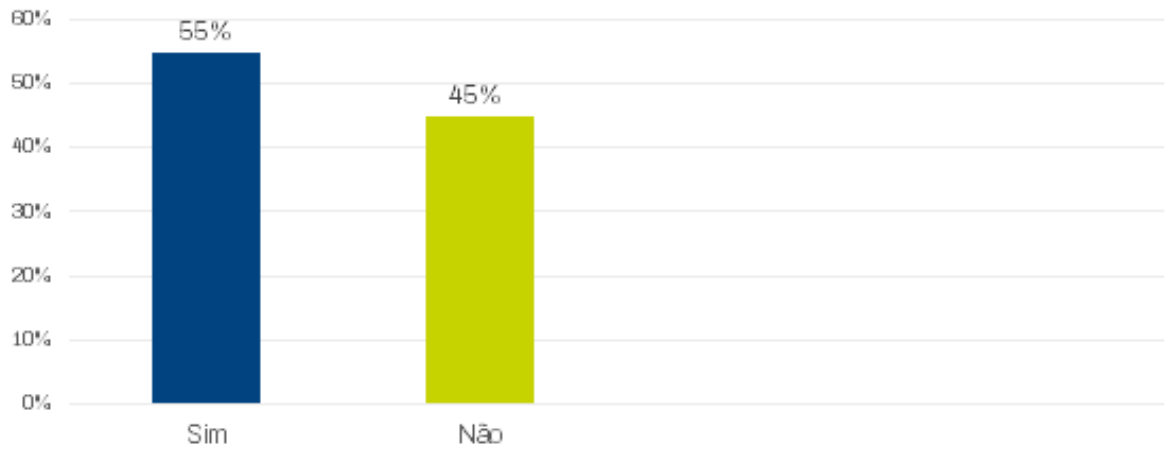

Gráfico 03: Conhecimentos Prévios

Fonte: Elaborado pelos autores (2021).

Sobre a mesma temática dos conhecimentos prévios, foi analisando cada etapa de ensino, verificando-se que $60,5 \%$ dos estudantes do Ensino Fundamental $2^{\circ}$ ciclo, não conheciam os temas abordados, para o Ensino Médio e Superior, como apresentado no gráfico 04, esse percentual diminuiu para 39\% e 14\% respectivamente. Vale ressaltar que, todos os discentes entrevistados da Educação Básica, são da rede pública de ensino.

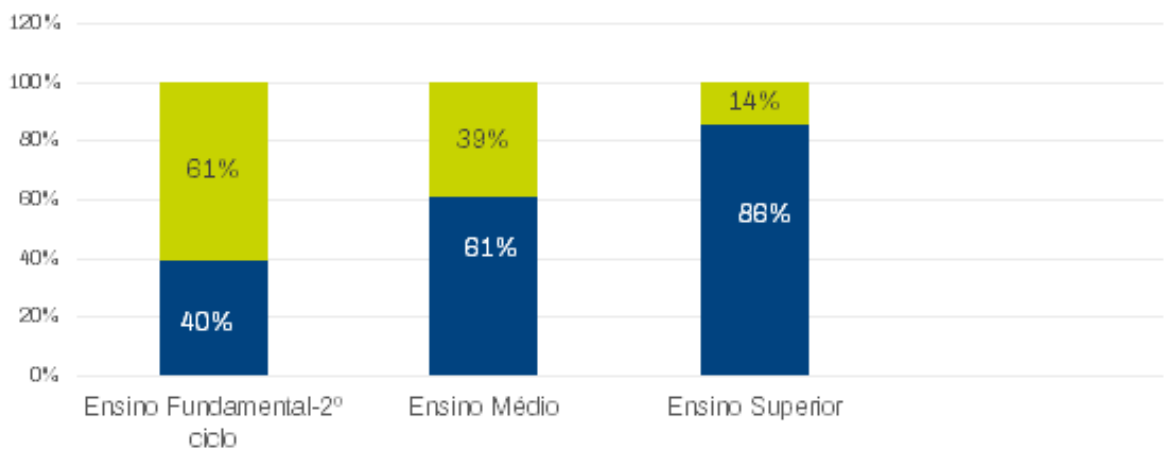

Gráfico 04: Conhecimentos prévios por etapa de ensino Fonte: Elaborado pelos autores (2021).

Fazendo uma análise crítica, sobre os resultados obtidos, a respeito dos conhecimentos prévios sobre a Física Moderna e Contemporânea, observa-se na Educação Básica, o número de estudantes sem esses conhecimentos é bem mais significativo 
que no superior, concordando com a pesquisa de Pereira (2013, p. 74), onde ele apresenta: "alunos da educação básica possuem conhecimentos superficiais sobre termos e teorias relacionadas à FMC e suas aplicações para a geração de tecnologias".

Com relação aos conceitos da Física Moderna e Contemporânea que foram trabalhados no romance, foi questionado junto aos estudantes se na opinião deles, os conceitos apresentaram-se com uma linguagem mais acessível que em livros conteudistas, e 75 (95\%) dos participantes, consideraram que sim, como representado no gráfico 05.

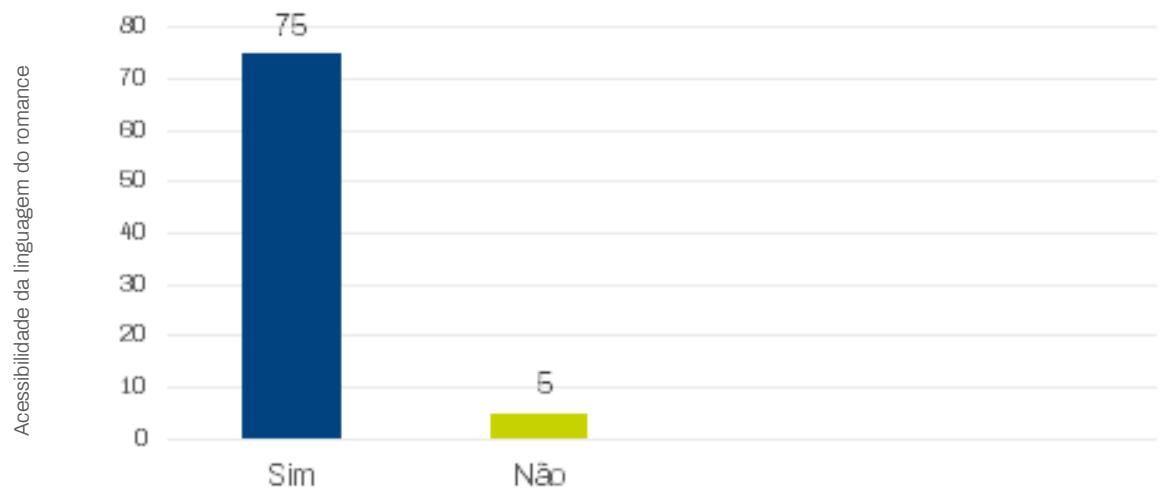

Gráfico 05: Linguagem do produto

Fonte: Elaborado pelos autores (2021).

O gráfico 06 mostra que 10,5\% dos estudantes do Ensino Fundamental - $2^{\circ}$ ciclo, afirmaram que a linguagem não está muito acessível, enquanto que no Ensino Médio 3,6\% dos discentes apresentaram a mesma opinião sobre o tema. Essa dificuldade de compreensão também foi observada na pesquisa de Diesel et al. (2017), na qual os estudantes apresentaram uma média de proficiência de apenas 39 de 100 pontos no pré-teste.

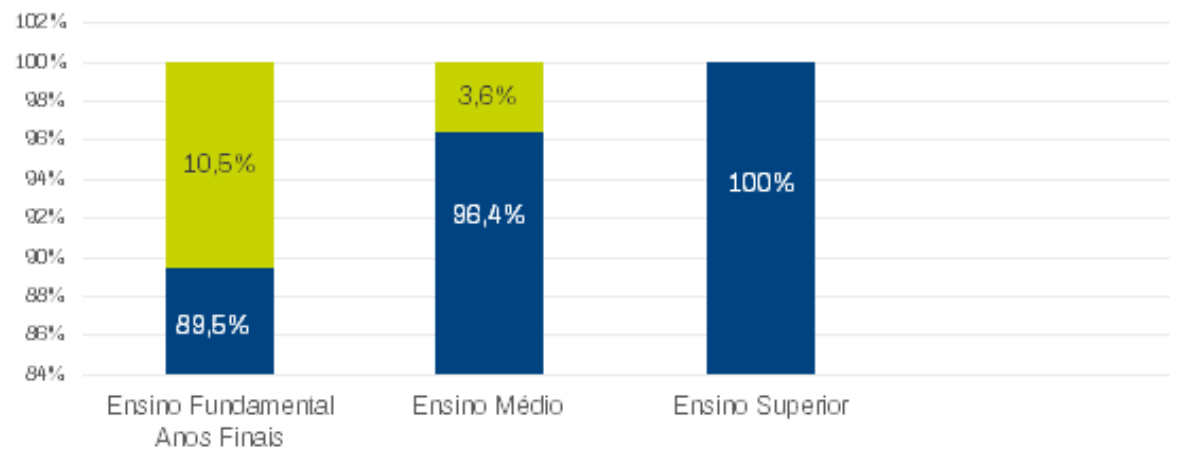

Gráfico 06: Aceitação da linguagem do romance Fonte: Elaborado pelos autores (2021). 
Em outro aspecto, foi indagado também aos estudantes, se após a leitura do romance seu interesse sobre a FMC, aumentou, permaneceu constante ou diminuiu, e $78,5 \%$ afirmaram que seu interesse aumentou e $21,5 \%$ que permaneceu constante, como apresentado no gráfico 07.

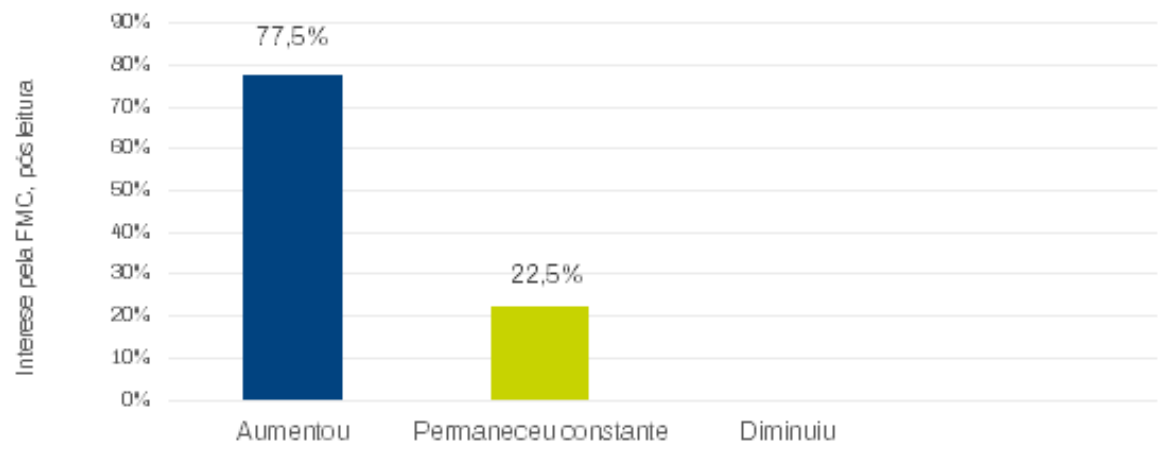

Gráfico 07: Motivação sobre a FMC

Fonte: Elaborado pelos autores (2021).

Observa-se, que a leitura do romance, despertou na maioria dos participantes da pesquisa, um interesse maior pela área. E analisando os resultados contrários, temos que $6 \%$ são estudantes do Ensino Médio, concordando com o trabalho de Araújo (2018), onde $13 \%$ dos estudantes da mesma etapa de ensino, também apresentaram menor curiosidade sobre os temas abordados, após utilização de paradidáticos.

Para o Ensino Fundamental $-2^{\circ}$ ciclo, a justificativa pode estar na leitura, pois, de acordo com Góis (2012), tudo gira em torno de uma boa leitura, se o estudante não ler com fluência, compreendendo tudo que está lendo, também não será motivado para outros aprendizados.

Mas é necessário maior interesse no que diz respeito ao ensino da leitura em si, é preciso pensar na leitura como prática social e não só como objeto de conhecimento, pois tudo gira em torno da leitura, em todos os momentos de nossa existência ela está presente (Góis, 2012 p.33).

Após as questões situacionais e as de avaliação do romance, são apresentadas sete questões conteudistas, sobre os assuntos trabalhados no romance: Princípio da dualidade onda-partícula, Efeito Fotoelétrico, Princípio da Incerteza, o gato de Schrödinger, Antimatéria, Emaranhamento quântico e o novo modelo atômico.

Os resultados obtidos mostraram que a maioria dos estudantes conseguiram êxito, na sua resolução. A questão que obteve maior percentual de acerto (90\%), foi a relacionada ao experimento conhecido como gato de Schrödinger, o qual é visto como um assunto bastante confuso, principalmente para os estudantes da Educação Básica.

O Emaranhamento quântico, foi o assunto com menor percentual de acerto (78,5\%), porém, tendo em vista, toda complexidade desse conceito, esse valor ainda pode ser considerado significativo. O percentual de acertos por questões está descrito no gráfico 08. 


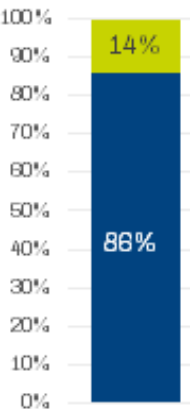

$\mathrm{COL}$

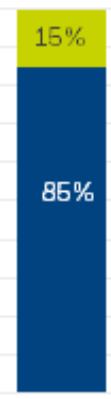

EF

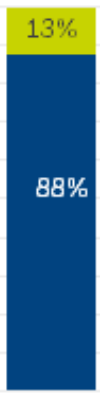

$\mathrm{Pl}$

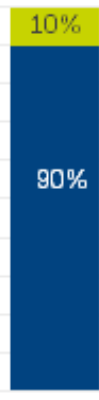

S

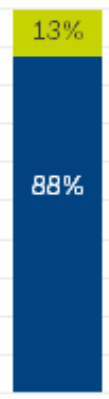

MA

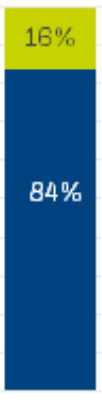

A

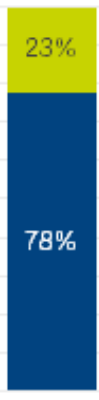

EQ

Gráfico 08: Resumo das questões conteudistas

Notas: COL: Comportamento Ondulatório da Luz; EF: Efeito Fotoelétrico; PI: Princípio da Incerteza; S: Schrödinger; MA: Modelo atômico; A: Antimatéria e EQ: Emaranhamento quântico.

Fonte: Elaborado pelos autores (2021).

Vale ressaltar, que todas as questões foram norteadas na leitura do romance: Memórias de Luiza, e que todas elas são apresentadas com todos os critérios científicos exigidos.

Analisando também os acertos por etapa de ensino, como visto no gráfico 09, verifica-se que no Ensino Fundamental $-2^{\circ}$ ciclo, foi a onde os estudantes apresentaram as maiores dificuldades, seguidos do Ensino Médio e Superior.

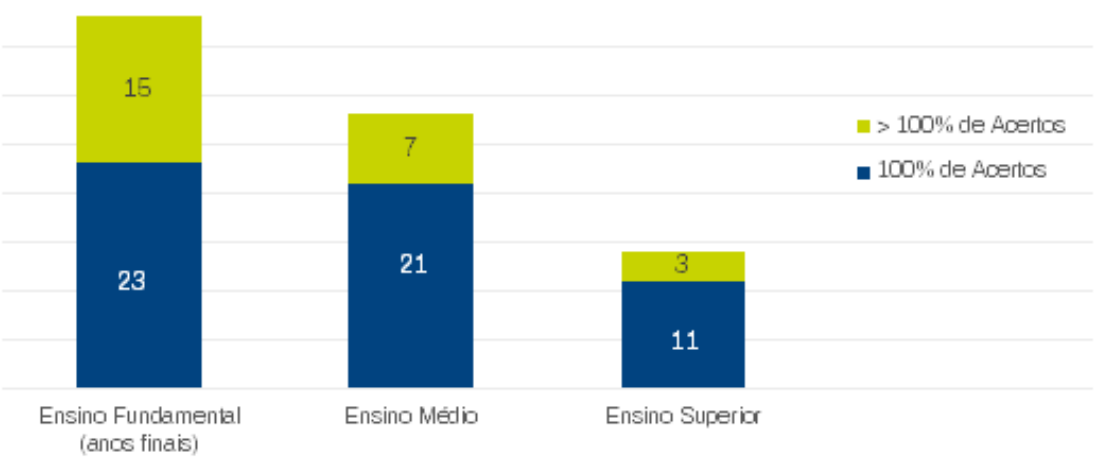

Gráfico 09: Percentual de acertos

Fonte: Elaborado pelos autores (2021).

Nota-se, que o número de estudantes com $100 \%$ de acertos nas questões conteudista aumenta de acordo com o grau de escolaridade, possivelmente devido a facilidade na interpretação textual e no entendimento da fenomenologia em razão dos conhecimentos prévios, mostrando sua importância como indicado na aprendizagem significativa. Porém, é importante observar a média de acertos das questões conteudistas é superior a $60 \%$ para o Ensino Fundamental $-2^{\circ}$ ciclo, $75 \%$ para o Ensino Médio e $78 \%$ para o Ensino Superior, em todos os casos é um valor considerável, tendo em vista a média escolar. 
Vale ressaltar também, o conteúdo trabalhado, o qual é apresentado pela literatura como avançado, principalmente para Educação Básica, como foi apresentado na pesquisa de Pereira (2013), na inserção de conceitos de FMC na Educação Básica.

É claro que nem todas as afirmações dos alunos estavam totalmente corretas em relação aos conceitos científicos, apresentando alguns "desvios" que foram sendo corrigidos no decorrer das discussões entre os próprios alunos e a orientação do professor (Pereira, 2013 p. 95).

Correlacionando esses resultados com os encontrados na literatura, temos na pesquisa de Costa e Rodrigues (2018), sobre a utilização de textos paradidáticos no ensino de Física: uma proposta metodológica, onde os autores apresentam que 84\% dos estudantes, após a leitura de paradidáticos, conseguiram responder todas as questões que lhes foram propostas, resultado semelhante aos dados da pesquisa.

Por fim, foi perguntado aos estudantes, se eles consideram, que para responder aos questionamentos sugeridos no questionário (as questões conteudistas), se o romance é uma boa fonte de pesquisa ou não, e $96,3 \%$ consideraram que sim, como apresentado no gráfico 10.

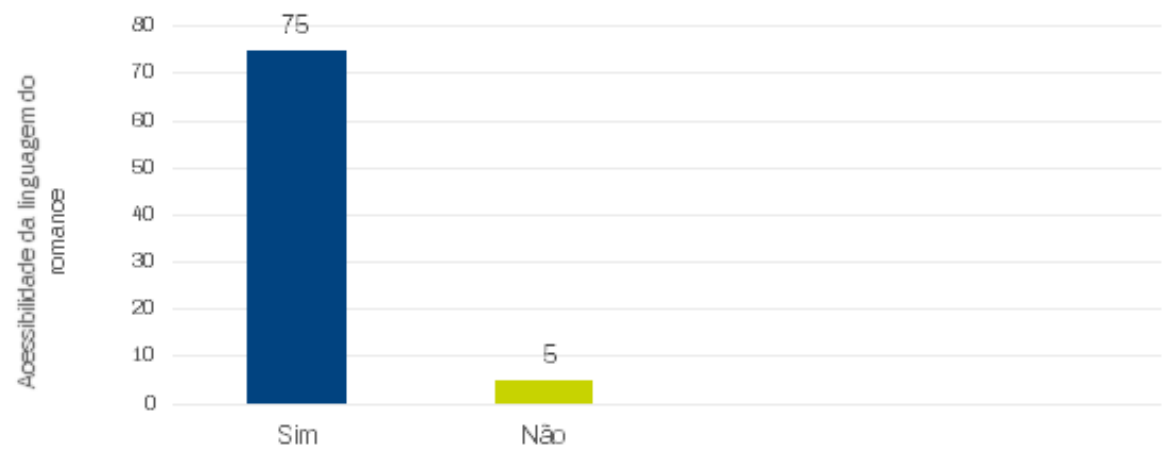

Gráfico 10: Avaliação da Ferramenta quanto ao conteúdo Fonte: Elaborado pelos autores (2021).

Esse percentual de 3,7\% referente aos estudantes do Ensino Fundamental $2^{\circ}$ ciclo, onde consideraram que o romance não é uma boa fonte de pesquisa para o estudo da Física Moderna e Contemporânea. Em relação aos participantes do Ensino Médio e Superior, todos acreditam que a leitura proposta é sim uma boa fonte de pesquisa. Concordando com o trabalho de Araújo (2018), onde 69,5\% dos estudantes do mesmo nível de ensino, afirmaram que a metodologia utilizada proporcionava uma boa compreensão do tema estudado.

Em suma, tornar a leitura, a experimentação, o diálogo e a interação discente um processo contínuo e diário permite desenvolver nos aprendizes uma capacidade crítica e efetiva na aquisição de novos conhecimentos. Os materiais paradidáticos, portanto, promovem essa situação, tão necessária no ensino de ciências em geral, e da Física em particular (Araújo, 2018, p.61). 
O romance, de acordo com os dados coletados, teve uma boa aceitação pelos estudantes, a maioria considera que este é um elemento motivador para o aprendizado da Física Moderna e Contemporânea, e ainda, que a linguagem é mais acessível, do que a utilizada nos materiais tradicionais.

Verifica-se, dessa forma, que é possível utilizar textos paradidáticos (romances), como ferramenta de ensino da Física Moderna e Contemporânea. E mais, que estes são suscitadores, de uma metalinguagem que favorece o processo de ensino aprendizagem.

\section{Considerações}

Com os dados coletados na pesquisa apresentada, desenvolvida de forma remota, através de um aplicativo, notou-se que os resultados obtidos foram satisfatórios com relação aos objetivos do romance. Ficou perceptível que o romance proposto é uma ferramenta de motivação e aprendizado para a Física Moderna e Contemporânea.

O estudo realizado permitiu vários ensinamentos, desde o replanejamento diante de uma situação inesperada, como no caso das aulas remotas, a utilização de materiais diversificados, como a leitura paradidática para ensinar Física, sendo possível ainda com o mesmo material atender a diferentes públicos, estudantes do Ensino Fundamental- $2^{\circ}$ ciclo, Ensino Médio e Ensino Superior conforme apresentado na pesquisa.

Verificou-se também, que a Física Moderna e Contemporânea pode sim ser trabalhada na Educação Básica, pois, de acordo com os dados coletados, estudantes que nunca tinham tido contato com os conceitos, conseguiram compreender e responder questões que abrangem a temática.

Conclui-se então, que a proposta metodológica foi bastante proveitosa atingindo os objetivos estabelecidos previamente, tanto como elemento motivador para o ensino da FMC, quanto como um material de estudo e aprofundamento do conteúdo.

No entanto, entende-se que o ensino de Física é desafiador, sendo que essa proposta não resolve todos os problemas, porém, pode ser um dos caminhos para consolidar melhor o ensino dessa ciência, que é tão encantadora e que tem muito a contribuir com a formação de cidadãos, mais críticos e participativos.

\section{Referências}

Araújo, R. F. G. (2018). A utilização de material paradidático no ensino dos conceitos iniciais de Óptica Geométrica. Universidade Federal Fluminense, Programa de Pós-Graduação do Mestrado NacionalProfissional em Ensino de Física. https://repositorio.unb.br/handle/10482/33274 .

Arruda, E. P. (2020). Educação remota emergencial: elementos para políticas públicas na educação brasileira em tempos de Covid-19. EmRede - Revista De Educação a Distância, 7(1), 257-275. https://bit.ly/3voR2k1

Costa, H. T. L. e Rodrigues, M. A. (2018). Textos paradidáticos no Ensino de Física: uma proposta metodológica. Revista Researchgate, 121-140. https://www.researchgate.net/ publication/327288923 
Diesel, A., Martins, S. N. e Rehfeldt, M. J. H. (2017). Estratégias de compreensão leitora: uma proposta de atividades desenvolvidas sob a perspectiva das metodologias ativas de ensino. Revista Diálogo Educacional, 17(55), 1662-1687. http://dx.doi.org/10.7213/1981416X.17.055.AO03.

Fonseca, J. J. S (2002). Metodologia da pesquisa científica. Fortaleza, UECE. https://bit.ly/3APIOiff

Góis, L. R. S. (2012). O Ensino da Leitura nas Escolas de Ensino Fundamental II. Centro Universitário de Brasília, Faculdade de Ciências da Educação e Saúde. https://bit.ly/3mVH7P4.

Gomes, E. F. (2011). O romance e a Teoria da Relatividade: a interface entre literatura e Ciências e Ciência no ensino de Física através do discurso e da estrutura da ficção. Universidade de São Paulo. https://bit.ly/3aGwiuw.

Moreira, M. A. (2007). A física dos quarks e a epistemologia. Revista Brasileira de Ensino de Física, 29 (2),161-173. https://doi.org/10.1590/S1806-11172007000200001

Moreira, M.A. (2010). Aprendizagem Significativa Critica. IIIEncontro Internacional sobre Aprendizagem Significativa. Lisboa: Peniche. https://www.if.ufrgs.br/ moreira/apsigcritport.pdf.

Moreira, M. A. (2021). Desafios no ensino da física. Revista Brasileira de Ensino de Física, 43(1), e20200451. https://doi.org/10.1590/1806-9126-RBEF-2020-0451.

Moreira, M. A. (2018). Uma análise crítica do ensino de Física. Revista Ensino de Ciências: Estudos Avançados, 32(94), 73-80. https://doi.org/10.1590/s0103-40142018.3294.0006.

Moura, F. P. (2017). Utilização de um livro paradidático no processo de ensino e aprendizagem de conceitos de Física. - Universidade Federal Rural do Semi-árido, Programa de PósGraduação do Mestrado Profissional de Ensino de Física (MNPEF). https://bit.ly/3aO89m4

Nunes, J. C. e Macedo, E. R. (2018) Introdução ao ensino da Física Quântica no Ensino Médio: um relato de experiência. Anais $V$ Congresso Nacional de Educação. Campina Grande: Realize Editora. https://editorarealize.com.br/artigo/visualizar/47683.

Pereira, F. C. (2013) Uma Estratégia Pedagógica para a Introdução de Conceitos de Física Moderna e Contemporânea. Programa de Pós-Graduação em Ensino de Ciências Naturais e Matemática do Centro de Ciências Exatas e Naturais da Universidade Regional de Blumenau. https://bu.furb.br//docs/DS/2013/355713_1_1.pdf.

Santos, N. G. A. Wisniewski, R. R. e Nonenmacher, S. E. B. (2017). Física, literatura e cotidiano: transposição didática da física dos físicos à da sala de aula. Revistes Catalanes amb Accés Obert - X Congresso Internacional sobre Investigaciónen Didáctica de las Ciencias, 11471152. Sevilla. https://raco.cat/index.php/Ensenanza/article/view/335637.

Setlik, J. e Higa, I. (2020). Gêneros discursivos na disciplina Física: ler e escrever através de uma perspectiva de interações sociais. Revista Cocar, 14(30), 1-19. https:// www.researchgate.net/publication/346325396 .

Silva, C. S. e Almeida, M. J. P. M. (2011). Física Quântica no Ensino Médio: o que dizem as pesquisas. Caderno Brasileiro de Ensino de Física, 28(3), 624-652. https://doi.org/10.5007/21757941.2011v28n3p624.

Zanetic, J. (1990). Física também é cultura. Tese (Doutorado) Faculdade de Educação da USP, São Paulo. https://repositorio.usp.br/item/000731157.

\section{Como citar em APA:}

Mouta, M. N., Dantas, G., Silva, M. S. \& Ramiro, A. J. (2021). O romance no ensino da Física Moderna e Contemporânea: uma proposta metodológica. Revista Iberoamericana de Educación, 87(2), 139-152. https://doi.org/10.35362/rie8724502 